\title{
Experimental study on shale fracturing assisted by low-temperature freezing
}

\author{
Zhong-Ying Han, Yuan-Fang Cheng, Xue-Liang Li, Chuan-liang Yan \\ School of Petroleum Engineering, China University of Petroleum (East China), Qingdao, Shandong 266580, China. \\ hanzbying@.upc.edu.cn,yfcheng@upc.edu.cn
}

\begin{abstract}
Under the cold impact of liquid nitrogen, the shale suffers from the significant freezing damage, which provides the possibility of liquid nitrogen fracturing. Moreover, shale fracturing assisted by liquid nitrogen can effectively reduce reservoir pollution. In this paper, the hydraulic fracturing experiments of natural shale samples frozen by liquid nitrogen were carried out to investigate the factors affecting the crack propagation of shale after low temperature fracturing. The results show that a large number of cracks or macropores form inside the natural shale sample after freezing treatment by liquid nitrogen. The fracture pressure of the shale decreases with increasing impact time at the beginning of the immersion time, and remains substantially stable after an immersion of 2 hours. When the freezing time increases, the crack initiation time increases accordingly. After low temperature impact, the fracture pressure of shale decreases with the increase of stress difference, but the cracking times vary with the stress with obvious regularity. It is easier to form main fracture with larger displacement on the premise of well-developed shale bedding.
\end{abstract}

KEYWORDS. Liquid nitrogen; Freezing; Hydraulic fracture; Fracture pressure; Fracture initiation time.

\section{open Access}

Citation: Han, Z-Y., Cheng, Y.F., Li, X-L., Yan, C-1.., Experimental study on shale fracturing assisted by low-temperature freezing, Frattura ed Integrità Strutturale, 47 (2019) 74-81

Received: 18.10 .2018

Accepted: 14.11 .2018 Published: 01.01.2019

Copyright: (C) 2019 This is an open access article under the terms of the CC-BY 4.0, which permits unrestricted use, distribution, and reproduction in any medium, provided the original author and source are credited.

\section{INTRODUCTION}

$\mathrm{T}$ he freezing and fracturing of the shale shocked by liquid nitrogen on rock mainly follows two stages: cold shrinkage and frost heave. The huge temperature difference caused by the freezing of liquid nitrogen makes the pore structure of the shale shrink and deform, resulting in thermal stress. At the same time, when the pore water freezes into ice, it expands in volume and produces frost heave. Under the combined action of thermal stress and frost heaving force, the pore structure of shale is destroyed and the cracks is generated [1-5]. Shale fracturing assisted by lowtemperature freezing is to form a certain crack network by the freezing and breaking mechanism of liquid nitrogen, and then perform hydraulic fracturing to improve the shale conductivity and increase fracturing effect.

Low temperature fracturing technology in the petroleum industry has still been in the experimental stage of exploration. In 1983, King [6] used gelatinous liquid carbon dioxide as a modification liquid to improve the in-place production of 
tight sand layer, and achieved good results without experimental verification. Mcdaniel et al. [7, 8] conducted a liquid nitrogen immersion test on coal rock in the laboratory. The results showed that low temperature fracturing might increase the production of coalbed methane and conduct field tests. Because of the existed natural cracks and obvious layering, the damage mechanism of shale after low-temperature impact is more complicated. In fully understand the failure mechanism of shale after low-temperature impact, many experts and scholars have conducted a lot of basic experimental research [911]. Cai et al. [12,13] conducted an experimental study on the damage of shale pore structure under the action of liquid nitrogen. In recent years, to meet the needs of low-temperature fracturing technology, many scholars began to analyze the physical and mechanical properties of shale after liquid nitrogen treatment through indoor experiments, as well as considered the influence of shale bedding orientation [14-16]. In the physical simulation of hydraulic fracturing, the researchers $[17,18]$ used artificial cement samples to simulate low-temperature cracking of shale, but there were also some differences, such as randomly distributed natural cracks and bedding, between artificial and natural samples. In this paper, the crack propagation characteristics of shale after low-temperature fracturing are analyzed by the hydraulic fracturing experiment of natural shale samples, and the factors affecting crack propagation are discussed.

\section{EXPERIMENTAL PROGRAM}

he sample was taken from the outcrop shale of Longmaxi Formation in a certain area. The outcrop shale is a natural extension of the Silurian Longmaxi Formation shale reservoir in the southeast of Guizhou, China. The shale mineral composition analysis was carried out by an X-ray diffractometer, and the results are shown in Fig. 1. The main component of the experimental sample is quartz, accounting for $52 \%$, followed by clay minerals, accounting for $17 \%$. Among the clay minerals, Illite is the main component, accounting for $60 \%$.

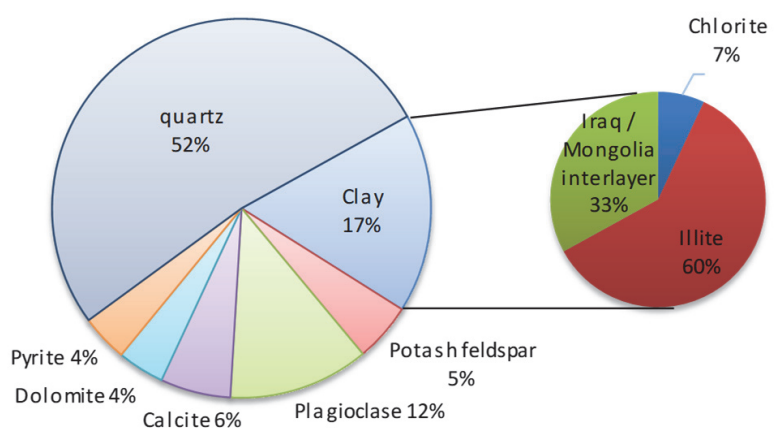

Figure 1: Shale mineral composition and its content.

\section{Shale tensile strength test}

Hydraulic fracturing is one of the prerequisites for the development of shale gas. The principle of shale hydraulic fracturing is to pump the fluid into the well by the ground high-pressure pump set with a displacement that greatly exceeds the absorption capacity of the formation, and then cause the high pressure near the bottom of the well. When the pressure is greater than the in-situ stress near the borehole wall and the tensile strength of the shale, cracks forms in the formation near the bottom of the well. The tensile strength of the shale characterizes the ultimate bearing capacity of the shale during tensile failure. The tensile strengths of the shale before and after freezing were determined before the hydraulic fracturing experiment. The results are listed in Fig. 2. It can be seen that the tensile strength of shale decreases by about $20 \%$ before and after freezing of liquid nitrogen, and the reduction of tensile strength is more conducive to the formation of cracks during fracturing.

\section{Shale fracturing experiment assisted by liquid nitrogen}

A true triaxial experimental system was used for liquid nitrogen fracturing test. It mainly includes liquid nitrogen selfpressurizing system, intermediate container, and true triaxial experimental equipment, as shown in Fig. 3. The experimental sample was cut from a cuboid shale rock to a dimension of $100 \mathrm{~mm} \times 100 \mathrm{~mm} \times 100 \mathrm{~mm}$, with the surfaces smoothed by grinding. The length of the open hole of simulated wellbore was $30 \mathrm{~mm}$, as shown in Fig. 4. 
The factors affecting fracturing efficiency of shale after liquid nitrogen cold impact treatment, such as the complexity of natural cracks, the displacement of fracturing fluid and the difference of ground stress, were mainly discussed. A comparison table of control variables was used to develop an experimental program, as shown in Tab. 1 , where $\sigma_{\mathrm{v}}$ is the vertical stress, $\mathrm{MPa}, \sigma_{\mathrm{H}}$ is the maximum horizontal principal stress, $\mathrm{MPa}$, and $\sigma_{\mathrm{h}}$ is the minimum horizontal principal stress, $\mathrm{MPa}$. To achieve the goal of fully extending of crack, the pre-freezing displacement is set to an intermediate value of 40 $\mathrm{ml} / \mathrm{min}$, and the order from low to high after freezing is $20 \mathrm{ml} / \mathrm{min}, 40 \mathrm{ml} / \mathrm{min}$ and $60 \mathrm{ml} / \mathrm{min}$. The liquid nitrogen treatment times are set as $1 \mathrm{~h}, 2 \mathrm{~h}$ and $3 \mathrm{~h}$, respectively.

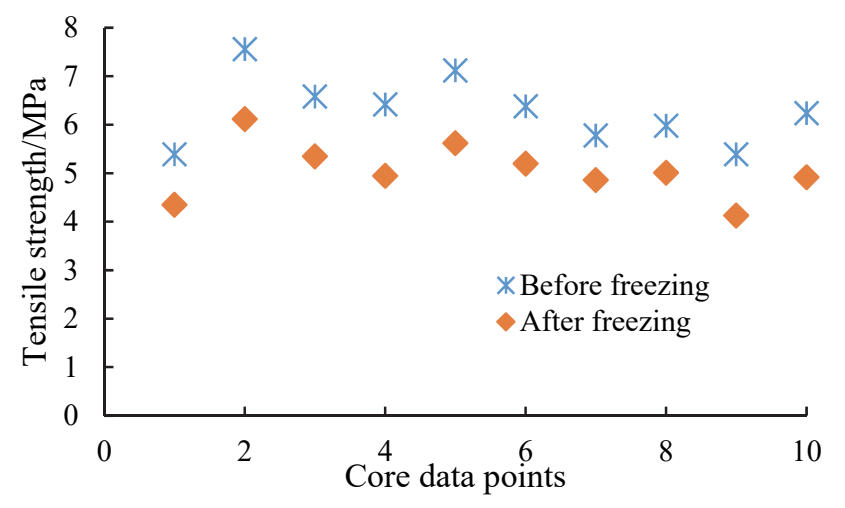

Figure 2: Change law of tensile strength before and after shale freezing.

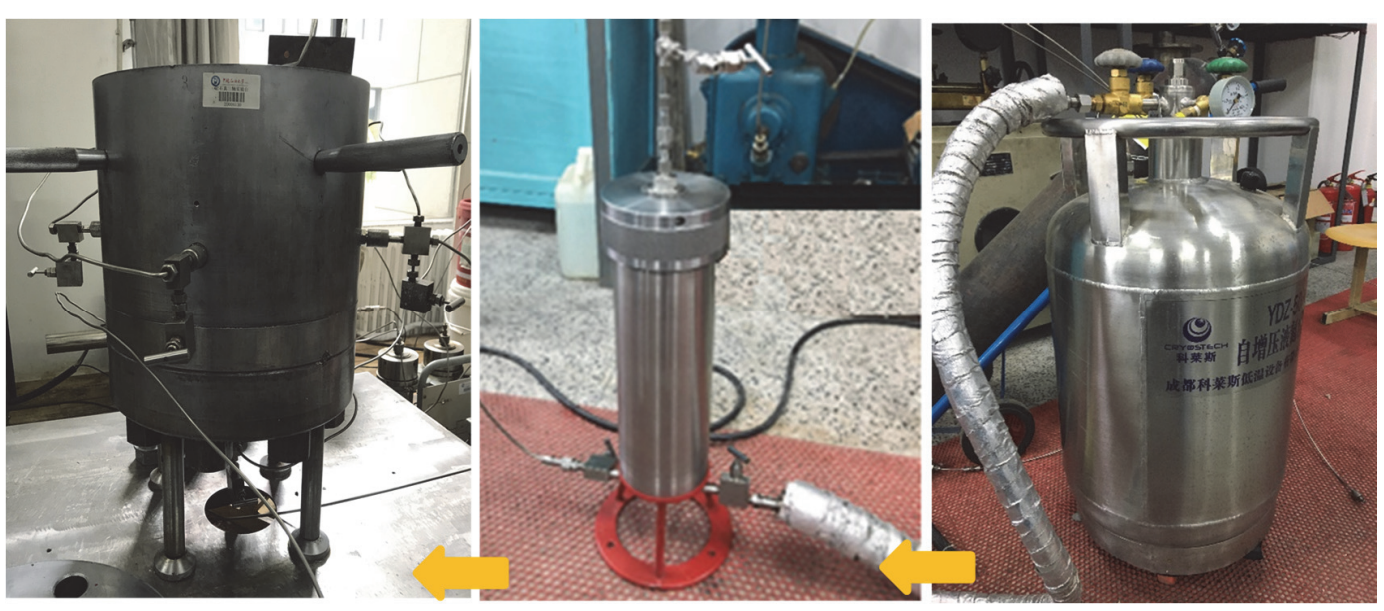

Figure 3: True triaxial experimental system for liquid nitrogen fracturing.

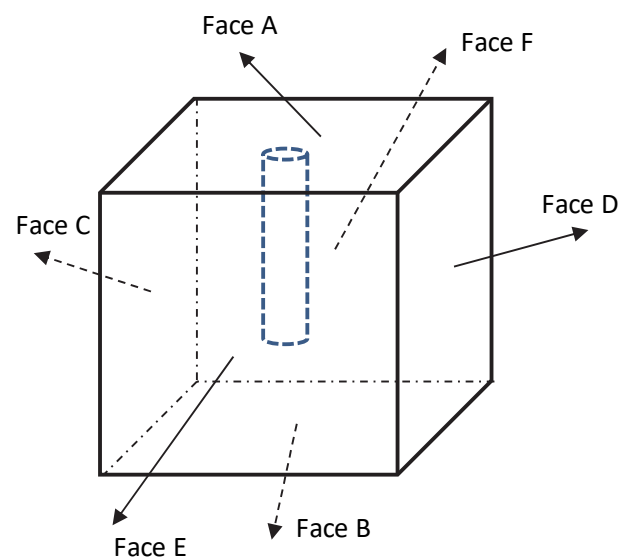

Figure 4: Sample basic model diagram. 


\begin{tabular}{ccccccc}
\hline $\begin{array}{c}\text { Experiment } \\
\text { number }\end{array}$ & $\begin{array}{c}\sigma_{\mathrm{v}} \\
/ \mathrm{MPa}\end{array}$ & $\begin{array}{c}\sigma_{\mathrm{H}} \\
/ \mathrm{MPa}\end{array}$ & $\begin{array}{c}\sigma_{\mathrm{h}} \\
/ \mathrm{MPa}\end{array}$ & $\begin{array}{c}\text { Stress } \\
\text { difference } \\
/ \mathrm{MPa}\end{array}$ & $\begin{array}{c}\text { Freezing time } \\
/ \mathrm{h}\end{array}$ & $\begin{array}{c}\text { displacement } \\
/ \mathrm{ml} / \mathrm{min}\end{array}$ \\
S-6 & 10 & 8 & 3 & 5 & 0 & 40 \\
SL-1 & 10 & 8 & 3 & 5 & 1 & 40 \\
SL-2 & 10 & 8 & 3 & 5 & 2 & 40 \\
SL-3 & 10 & 8 & 3 & 5 & 3 & 40 \\
SL-4 & 10 & 5 & 3 & 2 & 3 & 40 \\
SL-5 & 12 & 11 & 3 & 8 & 3 & 40 \\
SL-6 & 10 & 8 & 3 & 5 & 3 & 20 \\
SL-7 & 10 & 8 & 3 & 5 & 3 & 60 \\
\hline
\end{tabular}

Table 1: Shale fracturing test after liquid nitrogen freeze-thaw.

The main steps of the fracturing simulation experiment under liquid nitrogen freezing are as follows:

(1) Seven standard samples as shown in Fig. 4 were prepared according to the standard and labeled separately. A silica gel solution with a mass fraction of $4 \%$ was used as a fracturing fluid, and an appropriate amount of tracer was added.

(2) The sample was placed in a heat preservation container, and the liquid nitrogen was continuously injected into the sample simulation wellbore through the low-temperature pipeline by using the liquid nitrogen self-pressurization system, and the duration varied from $1 \mathrm{~h}$ to $3 \mathrm{~h}$ according to the experimental requirements.

(3) The sample had been placed at rest for a period of time after taken out from container, and then was placed in the main pressure-bearing cavity. Two steel blocks were placed on both Face A and Face B to adjust the height, and the upper cover of the experimenter was sealed and fasten with bolts.

(4) An air compressor and a pneumatic control valve were used to apply the in-situ stress. The pressure was maintained at $0.8 \mathrm{MPa}$ by the air compressor. The gas boosting device and the hydraulic pump were used to apply stress to the sample in three directions to a predetermined value. The load was applied smoothly to prevent pressure fluctuations during the whole process.

(5) After the three-direction stresses applied to the presupposed values and kept stably, a pipeline was connected to the reserved hole above the sample. The silica gel solution with a mass fraction of $4 \%$ was injected in by a displacement pump controlled by the servo motor, to simulate the pressure variation during the whole fracturing process. The real-time pressure information of the injected fluid was synchronously recorded by the computer.

(6) The pump was stopped when the experiment was finished. The wellbore pressure and the stress acting on the sample were unloaded in turn. The pressure in the hydraulic bladder was slowly released to zero to prevent damage to the equipment from instantaneous depressurization.

(7) After the sample was taken out from the autoclave, and the crack morphology after fracturing was observed in detail and the fracturing mechanism was discussed.

\section{EXPERIMENTAL RESULTS}

\section{Acoustic wave results}

A total of 7 samples were involved in the experiment. According to the experimental procedure, each sample was initially frozen by liquid nitrogen. From the experimental phenomena, the original bedding and natural cracks on the surface, especially on Face A, of the shale developed well after cold treatment by liquid nitrogen. The fractures showed a radial distribution along the simulated wellbore, and the natural fracture network was perfect. To detect the formation of cracks in detail, five points were randomly selected on Face $C$ and Face D, as shown in Fig. 5. The acoustic wave variations of the sample before and after the liquid nitrogen treatment on both sides of Face $\mathrm{C}$ and Face $\mathrm{D}$ were determined. Taking the sample SL-1 as an example, as shown in Fig. 6, the acoustic wave values of each monitoring point have decreased to some extent after liquid nitrogen cooling treatment, indicating that a large number of cracks or macropores have generated inside the sample after cold treatment. 
From the results of fracturing, main hydraulic cracks form near simulated wellbore, and extend along the direction perpendicular to the minimum horizontal principal stress, finally form a vertical fracture surface. Micro-cracks form on each face, and most of them extend in the direction of natural cracks and then cross each other to form a crack network. From the dissection of the sample after fracturing, the traces of the white tracer are clearly, indicating that liquid nitrogen enhances its permeability of shale.

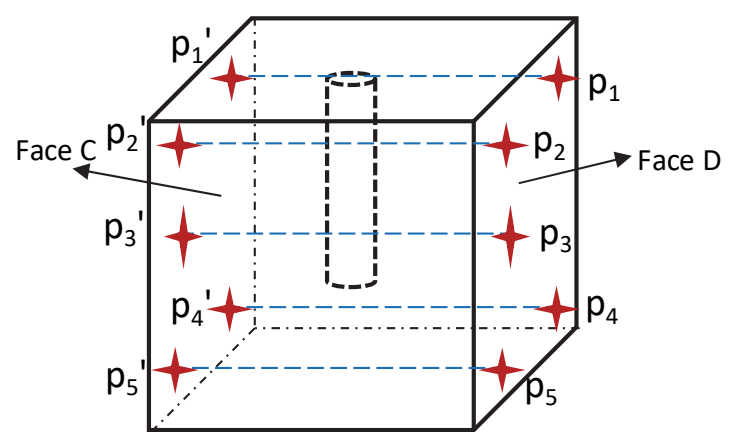

Figure 5: Schematic diagram of acoustic wave test points.

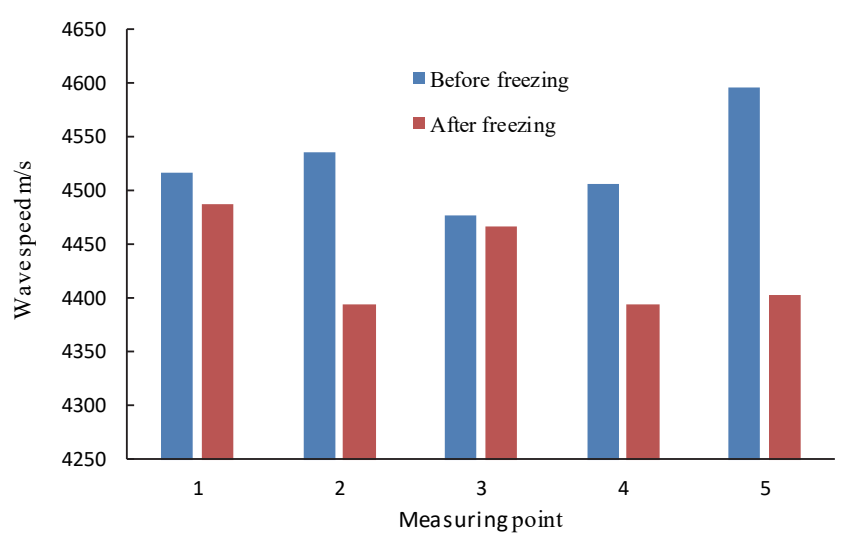

Figure 6: Acoustic wave results before and after freezing of Face C and Face D on SL-1 sample.

\section{Effect of liquid nitrogen cold treatment time}

The hydraulic fracturing simulations were carried out to study the effect of cold treatment time on fracturing effect. The fracturing construction curve of sample SL-1, SL-2 and SL-3, by changing the length of liquid nitrogen action time while maintaining the stress difference and displacement, are shown in Fig. 7. It can be seen that the fracture pressure is the highest after immersion for 1 hour in liquid nitrogen, about $21 \mathrm{MPa}$. After immersing for 2 hours and 3 hours, the fracture pressure remains basically unchanged as $10.8 \mathrm{MPa}$ and $10.5 \mathrm{MPa}$, respectively. This phenomenon shows that the fracture pressure decreases with the increase of impact time within a certain period of time. But this change is limited by a time effect. After immersion of 2 hours, the effect of the low temperature on the physical and mechanical properties of the sample did not change much as the treatment time prolonged.

The cracking time reflects that the pre-impact of liquid nitrogen mainly enhances the brittleness of shale. However, the late impact reduces the brittleness of shale and increases the plasticity, and it is not easy for cracking, and the cracking time is greatly increased by about 5 times. The crack gradually forms a cross-sewed network from the general macro-crack, and the fracturing effect is better at about $2 \mathrm{~h}$.

\section{Influence of stress difference}

The comparative experimental results of sample SL-3, SL-4 and SL-5 show that the fracture pressure of the sample decreases with the increase of the stress difference, under the condition of only changing the magnitude of the stress difference, as shown in Fig. 8. However, there is no obvious regularity about the initiation time affected by the stress difference. At the same time, the fracture-making ability increases gradually with the increase of the stress difference because the cross-sewed network gradually forms from the general macro-crack. 


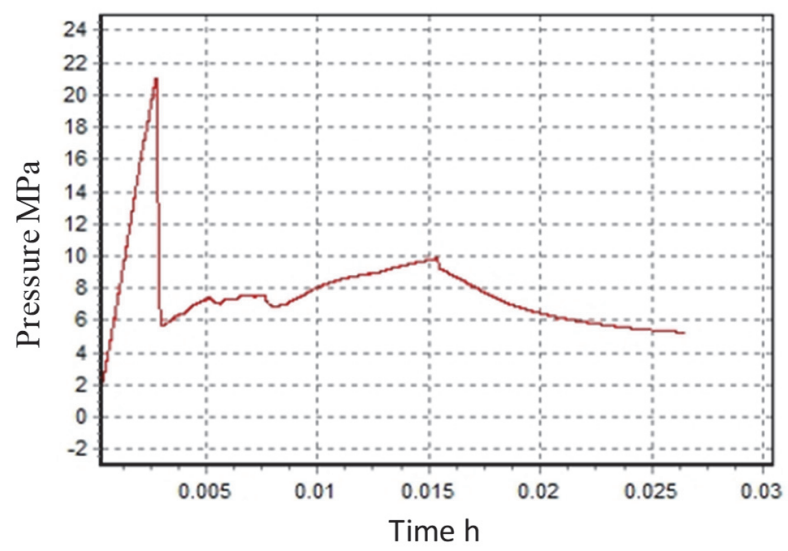

a) SL-1

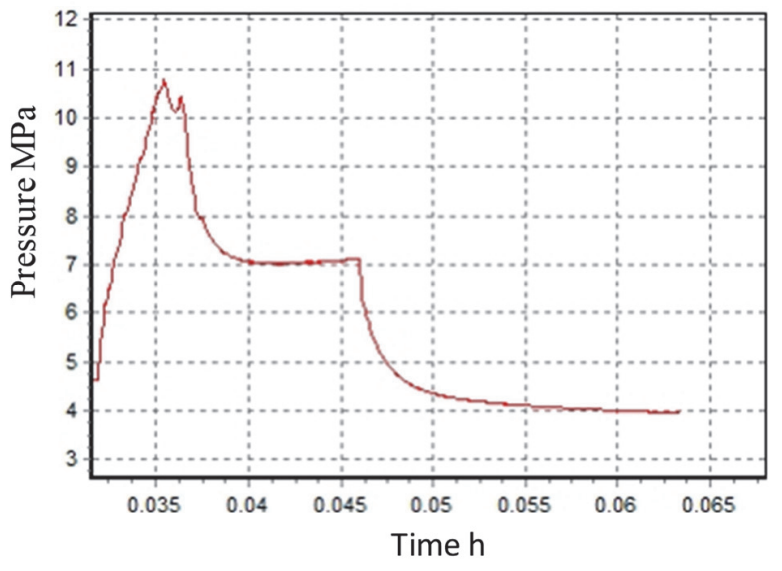

b) SL-2

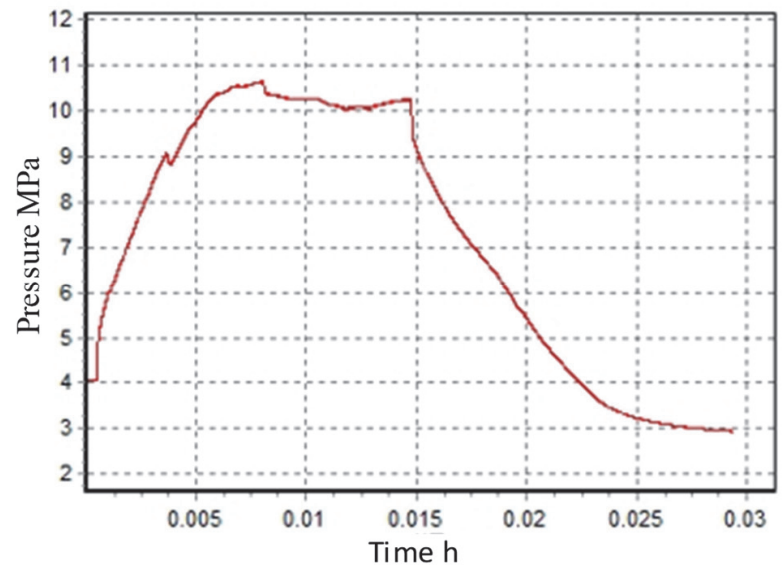

c) SL-3

Figure 7: Rock sample fracturing curve.

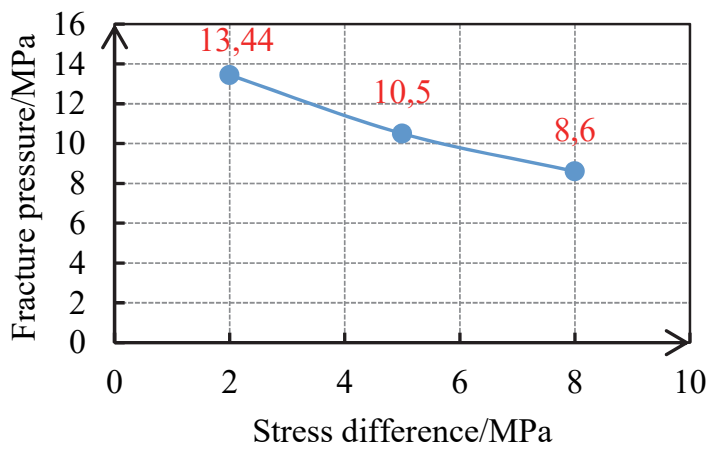

Figure 8: Curve of fracture pressure with stress difference.

\section{Influence of fracturing fluid displacement}

In comparisons of the experimental results of sample SL-3, SL-6, and SL-7, the following conclusion can be drawn that the fracture pressure increases as the displacement of the fracturing fluid increases, by changing the pumping displacement of the fracturing fluid while keeping other reference factors constant, as shown in Fig. 9. Similarly, there is no regularity in the initiation time with the change of displacement. From the point of view of fracture-forming ability, it is easier to form main fractures with larger displacement on the premise of well-developed shale bedding, as shown in Fig. 10. However, the effect of crack propagation in the formation of secondary seams under large displacement is not good. 
Therefore, to get a better fracturing effect, it is suggested that the larger displacement fracturing be adopted firstly to produce the main fracture, and then the lower displacement fracturing be used to develop the fracture network.

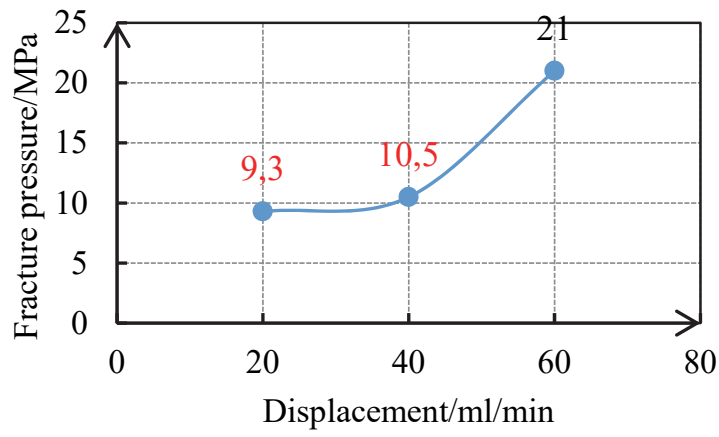

Figure 9: Curve of fracture pressure with displacement.
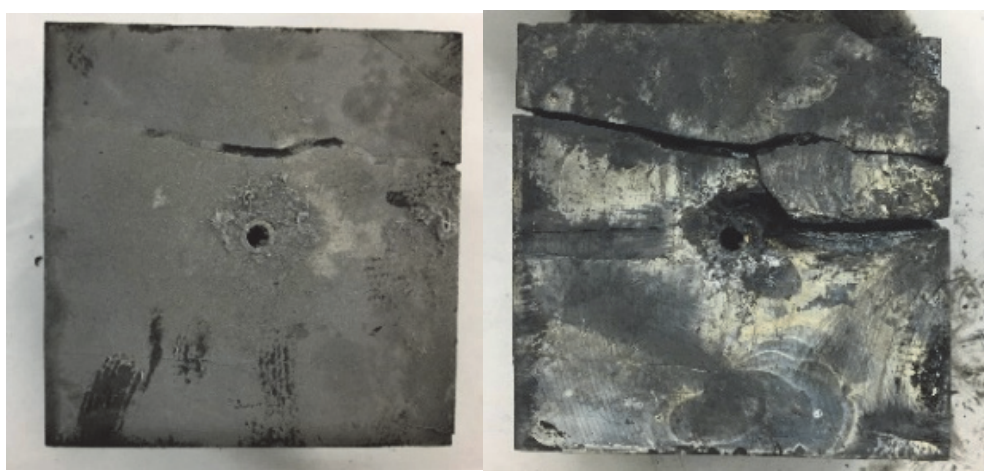

a) Before fracturing (Face $\mathrm{A}$ )

b) After fracturing (Face A)
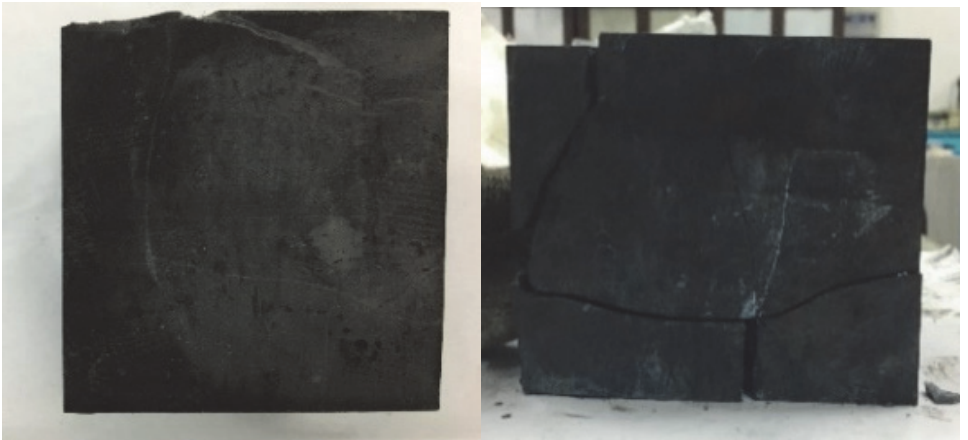

c) Before fracturing (Face C)

d) After fracturing (Face C)

Figure10: Morphology of the SL-7 sample before and after fracturing.

\section{CONCLUSION}

(1) The original bedding and natural cracks on the surface of the natural shale sample were further developed after the cold treatment by liquid nitrogen. The sound wave test results showed that a large number of cracks or large pores had generated inside the sample.

(2) The fracture pressure of the shale decreased with the increase of the impact time when the immersion time was short, and remained stable after immersion of 2 hours. When the freezing time extended, the crack initiation time increased accordingly.

(3) After low temperature impact, the fracture pressure of shale decreased with the increase of stress difference, but the effect of stress difference on initiation time was not obvious.

(4) From the perspective of crack-forming ability, under the premise of good developed bedding, the larger displacement was more likely to form the main crack inside the shale, while the effect of forming the secondary crack was not good. 


\section{FUNDING}

his research was financially supported by the National Natural Science Foundation of China (No. 51504280), the Fundamental Research Funds for the Central Universities (No. 16CX02022A), and the funds of China University of Petroleum talents introduction (No. YJ201601094).

\section{ACKNOLEDGEMENTS}

his work should be thankful for the help from Rock Mechanics Laboratory in China University of Petroleum (East China).

\section{REFERENCES}

[1] Inada, Y., and Yokota K. (1984). Some studies of low temperature rock strength. International Journal of Rock Mechanics \& Mining Sciences \& Geomechanics Abstracts, 21(3), pp.145-153. DOI: 10.1016/0148-9062(84)91532-8.

[2] Matsuoka, K. (1988). A laboratory simulation of rock breakdown due to freeze-thaw in a Maritime Antarctic environment. Earth Surface Processes and Landforms, 13, pp. 369-382. DOI: 10.1002/esp.3290130408.

[3] Bellanger, M., Homand F., and Remy, J.M. (1993). Water behavior in limestones as a function of pores structure: Application to frost resistance of some Lorraine limestones. Engineering Geology, 36(1-2), pp. 99-108.

DOI: 10.1016/0013-7952(93)90022-5.

[4] Chen, T. C., Yeung, M. R., and Mori, N. (2004). Effect of water saturation on deterioration of welded tuff due to freeze-thaw action. Cold Regions Science and Technology, 38(2), pp.127-136. DOI: $10.1016 /$ j.coldregions.2003.10.001.

[5] Ren, S.R., Fan Z.K., Zhang L., et al. (2013). Mechanisms and experimental study of thermal-shock effect on coal rock using liquid nitrogen. Chinese Journal of Rock Mechanics and Engineering, (Z2), pp. 3790-3794. (in Chinese)

[6] King, S. R. (1983). Liquid $\mathrm{CO}_{2}$ for the stimulation of low-permeability reservoirs. Soc. Pet. Eng., 11616, pp.145-151.

[7] Mcdaniel, B.W., Grundmann, S., Kendrick, W., et al. (1997). Field applications of cryogenic nitrogen as a hydraulic fracturing fluid. Journal of Petroleum Technology, 50(3), pp.38-39.

[8] Grundmann, S.R., Rodvelt, G.D., Dials, G.A., Allen, R.E. (1998). Cryogenic nitrogen as a hydraulic fracturing fluid in the devonian shale. SPE Eastern Regional Meeting. Society of Petroleum Engineers, Pittsburgh, Pennsylvania. Gupta.

[9] Hall, K. (2010). A laboratory simulation of rock breakdown due to freeze-thaw in a maritime Antarctic environment. Earth Surface Processes and Landforms, 13(4), pp.369-382. DOI: 10.1002/esp.3290130408.

[10] Nicholson D.T., and Nicholson, F. H. (2000). Physical deterioration of sedimentary rocks subjected to experimental freeze-thaw weathering. Earth Surface Processes and Landforms, 25(12), pp.1295-1307. DOI: 10.1002/1096-9837.

[11] Kim, K. M., and Kemeny, J. (2009). Effect of thermal shock and rapid unloading on mechanical rock properties. 43rd U.S. Rock Mechanics Symposium and 4th U.S.-Canada Rock Mechanics Symposium.

[12] Cai, C., Li, G., et al. (2014) Experiment study of rock porous structure damage under cryogenic nitrogen freezing. Rock and Soil Mechanics, 35(4), pp. 965-971. (in Chinese)

[13] Cai, C., Li, G., et al. (2014). Experimental study on effect of liquid nitrogen on rock failure during cryogenic nitrogen fracturing. Journal of China University of Petroleum, 38(4), pp. 98-103. (in Chinese)

[14] Jiang, L., Cheng, Y.F., Han, Z.Y., et al. (2018). Effect of liquid nitrogen cooling on the permeability and mechanical characteristics of anisotropic shale. Journal of Petroleum Exploration and Production Technology, (on line). DOI: $10.1007 /$ s13202-018-0509-5.

[15] Han, S.C., Cheng, Y.F., Gao, Q., et al. (2018). Experimental study of the effect of liquid nitrogen on shale physical/mechanical properties. ARMA, pp.18-273.

[16] Shi, X., Zhang, L., Cheng, Y.F., et al. (2017). Pore structure and mechanical property change of different rocks under nitrogen freezing. ARMA, pp.17-212.

[17] Cha, M.S., Yin, X.L., Kneafsey, T., et al. (2013). Cryogenic fracturing for reservoir stimulation-Laboratory studies. Journal of petroleum Science and Engineering, 124, pp. 436-450. DOI: 10.1016/j.petrol.2014.09.003.

[18] Wang, L., Yao, B.W., Cha, M.S., et al. (2016). Waterless fracturing technologies for unconventional reservoirs opportunities for liquid nitrogen. Journal of Natural Gas Science and Engineering, 35, pp.160-174.

DOI: 10.1016/j.jngse.2016.08.052. 